Considerable differences in susceptibility towards denaturation were observed. Haemoglobin $\mathrm{C}$ ( $\beta 6$ Glu $\rightarrow$ Lys) and haemoglobin S ( $\beta 6$ Glu $\rightarrow$ Val) show sigmoid 'melting' curves with the point of inflexion at about $40^{\circ} \mathrm{C}$. Haemoglobin $\mathrm{A}$ shows a point of inflexion some $5^{\circ} \mathrm{C}$ higher, and haemoglobin $A_{2}\left(\alpha_{2} \delta_{2}\right)$ seems to be the most stable of the haemoglobins investigated, 'melting' at about $55^{\circ} \mathrm{C}$. Addition of haemoglobin $\mathbf{A}_{2}$ to haemoglobin $\mathbf{C}$ and haemoglobin $S$ (4-10\% of the total) caused a large increase in the apparent 'melting' temperature. The effective amount of the haemoglobin $A_{2}$, assuming that the stability of the hybrid $\alpha_{2} \beta \delta$ is the same, cannot account for the full change observed in the denaturation profile.

Fluorescence measurements at the fixed temperature gave complementary results, with haemoglobin $A_{2}$ less than $5 \%$ denatured in the time in which the fluorescence change for haemoglobins $\mathrm{C}$ and $\mathrm{S}$ is complete, and haemoglobin $A$ about $50 \%$ denatured. The rates of change of fluorescence for haemoglobin $\mathbf{C}$ and haemoglobin $\mathbf{S}$ are identical. The plot of fractional change of fluorescence with time gives sigmoid curves, which suggests that, unlike myoglobin, denaturation is not first-order (Tanford, 1968; Acampora \& Hermans, 1967). At these concentrations the haemoglobins are predominantly in the dimeric form (Guidotti, 1967). All the haemoglobins studied had the same $\alpha$-chain, hence the denaturation of the $\alpha$-chain is not the rate-determining step, and if there is no co-operativity the order of susceptibility to denaturation must be $\alpha>\beta^{\mathrm{c}}=$ $\beta^{\mathbf{S}}>\beta^{\mathbf{A}}>\delta$. The denaturation of either chain, unless quenching by the adjacent chain masks completely, should result in some change in the fluorescence, which is not observed in the results for haemoglobin $\mathbf{A}_{2}$. It is therefore likely that some cooperative effect is being observed.

These experiments suggest that haemoglobin $\mathbf{A}_{2}$ may be involved in the stabilization of other haemoglobin components, and it is notable that the relative amount of this haemoglobin is increased in sicklecell-trait carriers (Wrightstone, Huisman \& Van Der Sar, 1968).

Acampora, G. \& Hermans, J. (1967), J. Am. chem. Soc. 89, 1543.

Guidotti, G. (1967). J. biol. Chem. 242, 3685.

Tanford, C. (1968). Adv. Protein Chem. 23, 122.

Wrightstone, R. N., Huisman, T. H. J. \& Van Der Sar, A.

(1968). Clinica chim. Acta, 22, 593.
The Effect of Organic Phosphates on the Reactions of Haemoglobin and Oxyhaemoglobin (Garboxyhaemoglobin) with Carbon Dioxide

By M. PaCe and L. Rossi-Bernardi (Institute of Organic Chemistry, University of Milan, Milan, Italy) and F. J. W. RovGHTON. (Laboratory of Biophysical Chemistry and Colloid Science, University of Cambridge, Cambridge CB2 3RJ, U.K.).

Many haemoglobins react with $\mathrm{CO}_{2}$ to form carbamates. The combination at physiological $\mathrm{pH}$ values occurs, at least for horse haemoglobin, and presumably also for human and bovine haemoglobin (the other species investigated) with the terminal amino groups of the $\alpha$ and $\beta$ chains. The reaction is greater with haemoglobin than with oxyhaemoglobin (or carboxyhaemoglobin), i.e. is oxygenlinked. Organic phosphates, e.g. 2,3-diphosphoglycerate and ATP, are also differentially bound (Benesch \& Benesch, 1969) and interfere with the oxygen-linked carbamate reactions at physiological $\mathrm{pH}$ values (Bauer, 1969), probably by combining at or near the terminal amino groups of the $\beta$ chains. To test this view we have determined $F$, the extra carbamate per haem molecule, at various $\mathrm{pH}$ values but constant $\mathrm{CO}_{2}$ partial pressure and temperature $\left(37^{\circ} \mathrm{C}\right)$, from the difference in total $\mathrm{CO}_{2}$ between haemoglobin and oxyhaemoglobin (or carboxyhaemoglobin) measured by a new micro-equilibration technique, for: (1) haemolysed blood; (2) organic-phosphate-free human and bovine haemoglobins; (3) as (2) but with various added amounts of diphosphoglycerate or ATP. The total $\mathrm{CO}_{2}$ content of the liganded (carboxy) haemoglobin is the same for (1), (2) and (3) at any given $\mathrm{pH}$ between 7.0 and 7.6. $F$ for (1) and (3) is half its value for (2) with human haemoglobin. With bovine haemoglobin, $F$ for (1) is the same as for (2). These results confirm that (a) organic phosphates under physiological conditions interfere with combination of $\mathrm{CO}_{2}$ with human haemoglobin, in agreement with Bauer's (1969) views; (b) diphosphoglycerate and ATP combine at or near two out of four of the terminal amino groups of the human haemoglobin molecule; (c) diphosphoglycerate and ATP (up to the molar ratio, so far investigated, of $2 \mathrm{~mol}$ of $P_{1} /$ haemoglobin tetramer) do not affect the $\mathrm{O}_{2}$-linked reactions of the other two terminal amino groups; (d) there is no apparent reaction between diphosphoglycerate or ATP with oxyhaemoglobin or carboxyhaemoglobin at or near any of the four terminal amino groups. The above values of $F$ agree generally with the results obtained by other methods, i.e. direct chemical determination (Ferguson, 1936) and indirect calculation from the 
specific effect of $\mathrm{CO}_{2}$ on the oxyhaemoglobin equilibrium curve (Rossi-Bernardi \& Roughton, 1970).

Bauer, C. (1969). Life Sci. 8, 1041.

Benesch, R. \& Benesch, R. E. (1969). Nature, Lond., 221, 618.

Ferguson, J. K. W. (1936). J. Physiol., Lond., 88, 40.

Rossi-Bernardi, L. \& Roughton, F. J. W. (1970). J. Physiol., Lond. (in the Press).

Two New Pathological Haemoglobins: - Olmsted $\beta 141$ (H19) Leu $\rightarrow$ Arg and Malmö $\beta 97$ (FG4) His $\rightarrow$ Gln

By P. A. Lorkin and H. LehmanN (Medical Research Council Abnormal Haemoglobin Unit, Department of Biochemistry, University of Cambridge, Cambridge CB2 $1 Q W, U . K$.$) and V.F.FAIRBanks$ (Mayo Clinic, Rochester, Minn., U.S.A.) and G. Berglund and T. Leonhardt. (Malmö General Hospital, Malmö, Sweden).

We have examined two abnormal human haemoglobins that are representative of two groups of pathological haemoglobins (Perutz \& Lehmann, 1968). One of these comprises unstable haemoglobins that are associated with inclusion-body anaemia (Lehmann \& Carrell, 1969). These haemoglobins have mutations that result in the haem being less strongly bound and they are more susceptible to oxidation than normal. Many of the unstable haemoglobins have mutations in the lining of the haem 'pocket' (Perutz et al. 1968a; Perutz, Muirhead, Cox \& Goaman, 1968b) involving the substitution of a non-polar residue by another of different size or by a polar residue. We have examined haemoglobin Olmsted described by Fairbanks, Opfell \& Burgert (1969), which appears to have a Leu $\rightarrow$ Arg mutation at position 141 (H19) of the $\beta$-chain. This is in a position homologous with that of the $\alpha$-chain-unstable haemoglobin Bibba $\alpha 136$ (H19) Leu $\rightarrow$ Pro (Kleihauer et al. 1968).

Another group of pathological haemoglobins associated with erythraemia (polycythaemia) is characterized by an increased oxygen affinity and decreased haem-haem interaction. Here the mutations are found mainly in the regions of the $\alpha 1 \beta 2$ contacts of the tetramer. We have identified a new haemoglobin of this type, Malmö $\beta 97$ (FG4) His $\rightarrow$ Gln, discovered in a study of the inheritance of polycythaemia in four generations of a Swedish family.

Fairbanks, V. F., Opfell, R. W. \& Burgert, E. O. (1969). Am.J. Med. 46, 344.
Kleihauer, E. F., Reynolds, C. A., Dozy, A. M., Wilson, J. B., Moores, R. R., Berenson, M. P., Wright, C. S. \& Huisman, T. H. J. (1968). Biochim. biophys. Acta, 154, 220.

Lehmann, H. \& Carrell, R. W. (1969). Br. med. Bull. 25, 14.

Perutz, M. F. \& Lehmann, H. (1968). Nature, Lond., 219, 902.

Perutz, M. F., Muirhead, H., Cox, J. M., Goaman, L. C. G., Mathews, F. S., McGandy, E. L. \& Webb, L. E. (1968a). Nature, Lond., 219, 29.

Perutz, M. F., Muirhead, H., Cox, J. M. \& Goaman, L. C. G. (1968b). Nature, Lond., 219, 139.

\section{Haemoglobin Synthesis in Thalassaemia}

By D. J. Weatherall and J. B. Clegg. (Department of Medicine, University of Liverpool, Liverpool $L 693 B Y, U . K$.)

The thalassaemias are a series of genetically determined disorders of haemoglobin synthesis, which all result from a defective rate of production of either the $\alpha$-or $\beta$-peptide chains of haemoglobin. Haemoglobin synthesis in vitro has been studied in reticulocytes obtained from thalassaemic patients and compared with that in non-thalassaemic reticulocytes. The parameters measured include the overall rate of $\alpha$-and $\beta$-chain production, the magnitude and properties of any excess of globin chains that are produced, the rate of globin chain assembly and, more recently, the rate of chain initiation.

The results of these investigations indicate that in each form of thalassaemia there is either a partial or total decrease in the rate of synthesis of one of the globin chains. No fragments of chains have been isolated from the cells of these patients. The assembly time of the globin chains has been measured and appears to be normal despite the marked decrease in the rate of chain synthesis. An attempt has been made to examine the distribution of nascent $\alpha$ - and $\beta$-chains on polyribosomes of different sizes with the object of studying the process of initiation in thalassaemic cells. Preliminary studies indicate that $\alpha$-and $\beta$-chains from nonthalassaemic individuals are synthesized on different-sized polyribosomes.

The results obtained to date are compatible with a decreased rate of mRNA production of a defect in chain initiation as the underlying genetic defect in some forms of thalassaemia. 